\title{
Understanding Chinese International Doctoral Students in New Zealand: A Literature Review of Contemporary Writings about Chinese Overseas Research Students
}

\author{
New Zealand Journal of Teachers' Work, Volume 13, Issue 2, 118-133, 2016
}

\section{QUN DING}

School of Education

Auckland University of Technology

\begin{abstract}
The number of Chinese students studying abroad has increased. Chinese international students have constituted the largest proportion of overseas students in New Zealand (Zhang, 2013). Little research has been done concerning those undertaking doctoral study. The study I have proposed to do thus intends to explore the experiences of Chinese doctoral students studying full-time at New Zealand universities. In this article I review literature on the Chinese international research student experience, in terms of their motives for studying abroad, and their university lives. Much research on the intercultural learning experience has adopted an adaptation perspective and has been more focused on negative experiences, thus strengthening the usual stereotype of students with learning and social deficits. In contrast, using a self-formation paradigm, this proposed study will perceive them as active agents and spotlights how they deal with challenges and difficulties and how they develop themselves in the process.
\end{abstract}

Keywords

Higher education; Chinese overseas doctoral students; student agency; motivation and supervision

\section{INTRODUCTION}

This proposed study will explore the experiences of Chinese doctoral students studying full-time at New Zealand universities. The narratives will start with their motives for choosing to study in New Zealand and include their experiences within and beyond the university environment, as well as the influence of learning on them (e.g. identity and social networks). A holistic understanding of their experiences in New Zealand implies links between their biography, past and present, public and private, and education as well as wider social structure (e.g. cultures and academic practices) in Chinese and New Zealand societies. 
The majority of Chinese international students were born in the 1980s and 1990s. They have grown up in a continually changing society. Chinese society has undergone significant changes since the early 1980 s when the government released a new 'open door' policy and initiated Chinese economic reforms. Many of these changes have social and ideological aspects (Wang, 2012). Some of the visible social changes have been the rapid growth of economy, the intense transformation of social structure, the implementation of one child policy, growing emphasis on materialism and consumption, urbanisation and the accessibility of Western culture (Lian, 2014; Moore, 2005). These social changes are also seen as forces inducing changes in the ideology of the younger generation (Lian, 2014), among which individualism is evident (Moore, 2005). A quantitative study by Sun and Wang (2010) on the influence of social changes on the values of Chinese people living in Shanghai has shown that compared to older generations, the younger generations hold more modern values: are more secular; more individualistic; and prioritise personal development. That is, the younger generations are generally labelled as the carriers of individualistic values in China. Ma, Hu \& Goclowska (2016) propose a similar stance in their quantitative research on the cultural orientations of different generations of Chinese employees in China.

Current research on Chinese generations suggests, however, that while confronting various social forces and competing values, younger generations and particularly the 1980s cohort experienced contradictory psychological states (individualism versus collectivism and traditional versus modern values) (Lian, 2014; Moore, 2005). Croll (1995) suggests that this is due to a lack of patterns and cues guiding new behaviour in rapidly changing Chinese society. Moreover, several studies on Chinese generations tend to acknowledge that there are specificities and stratifications within a generation. Different members of each generation would have individual experiences (Lian 2014). Therefore, despite there being no consensus about how to define generations in China (Sun \& Wang, 2010), it is possible to link societal contexts and personal situations to explore the experiences of group members (Lian, 2014).

Current literature also tends to be qualitatively based and uses a holistic approach to understanding Chinese international students, linking academic study and socio-cultural life, and combining Western theoretical frameworks with Confucian heritage cultures. For instance, Zhou (2014) and Zhang (2016) combine Western theories with the lens of Confucian culture to examine Chinese doctoral students' motivations and transition experiences in higher education in the United States. Goff and Carolan (2013) also attach significance to the interplay between Western culture, Chinese culture and communism in the formation of Chinese postgraduate student couples' lives in the United States.

The study I propose to do will use Wenger's (1998) communities of practice (CoP) theory as a theoretical framework, to explore the experiences of Chinese doctoral students in New Zealand. The core of this theory is to perceive learning as a process of social participation. Wenger points out that participation means not only "engagement in certain activities with certain people", but also "a more encompassing process of being active participants in the practices of social communities and constructing identities in relation to these communities" (p.4). Those studying overseas are placed within educational institutions, families, societies, and cultures, each of which can be 
seen as a community of practice. According to CoP theory, four major themes emerge: 'learning as belonging', 'learning as experience', 'learning as doing' and 'learning as becoming' (Wenger, 1998, p.5). Following the themes, key concepts in this study are subjectivity, reflexivity, agency and identity (outside the scope of this article). Some recent studies have shown awareness of the importance of utilising these concepts in shaping the Chinese international student experience (e.g. Gu \& Schweisfurth, 2015; Ye \& Edwards, 2015).

Much of previous Western literature has ignored Wenger's (1998) CoP theory and has highlighted the negative Chinese international student experience, helping to build a stereotype image of Chinese international students - being 'othered' and 'problematic' learners (Ye \& Edwards, 2015). Confucianism in these accounts can be seen as a negative factor undermining Chinese students' academic performance and thwarting their interaction with locals in host countries. This may be only part of the story.

Kennedy's (2002) work on adult Chinese learners in Hong Kong summarised the re-interpretations of Confucian beliefs and values relating to individuality in learning, rote learning and group work. These reinterpretations have demonstrated the Confucian emphasis on the responsibility of the individuals within the group, and the benefits of rote learning to assist learning. Kennedy concludes that they have a positive influence on learning, suggesting that the negative aspect of Confucianism is only part of the story.

It is important not to focus only on the negative aspects of Chinese overseas doctoral students' experiences, but also to consider positive ones, such as how they deal with challenges and difficulties and how they develop themselves in the process. They can be perceived as active agents, having the ability to reflect, participate, construct identities, articulate what they do and who they are.

In this article, a review of literature on Chinese international research student experience is undertaken to provide the basis for this research. The rest of this article is organised as follows: first, I review relevant literature on Chinese international students' motives for pursuing academic learning in a foreign country; then I review the literature related to their university life, focusing on their interaction with supervisors and their coping strategies for participating in host academic practices; and last, I conclude with a brief account of situating this research project within the literature.

\section{MOTIVES FOR PURSUING ACADEMIC LEARNING IN A FOREIGN COUNTRY}

There is a considerable body of research on Chinese students' motives for studying abroad. Current literature is best described by using a push-pull framework. Push forces are factors in the home country that drive students away from their country to study abroad. Pull forces operate within the host country and draw them to a particular country to study (Mazzarol \& Soutar, 2002). The former include economic wealth, a lack of adequate educational opportunities, intense competition for university places in China, a lack of competence and family influence. The pull factors involve university reputation, programme and staff quality as well as immigration possibilities (Azmat et al., 2013; Edwards \& Ran, 2006; Leder \& Forgasz, 2004; Zhang, 2013; Zhou, 2014). 
In the push-pull framework, I prefer to use 'forces' rather than 'factors' because I perceive the process of making a decision to leave home and study abroad not as static but as dynamic. Students' decision to pursue academic learning in a foreign country results from the interaction between forcescontextual, institutional and individual. As Zhou (2014) concludes in her study on Chinese doctoral students in the US, the interaction between sociocultural context and individuals helps shape learning motivation over time. Thus, in this research, I explore Chinese doctoral students' motivations for learning within the life course context, combining their past and present with their imagined future.

Regarding motivation for learning, current literature is generally described by using a two-way typology: instrumental orientation/extrinsic motivation and learning orientation/intrinsic motivation. These two motives are termed 'motive to attend' and 'motive to learn' (Lovell, 1989, p.19). The former suggests that adults' motives for becoming learners come from external factors and have individual hidden purposes that are not related to learning itself. Conversely, the latter is referred to as learning for its own sake. The two types of motivation are used as a general device to facilitate the analysis of adults' learning motives (Swain \& Hammond, 2011).

Similarly, some researchers employ the general device of the two types of motivation to explain Chinese students' motivations for studying overseas (e.g. Zhou, 2014; Edwards \& Ran, 2006). In their research into the needs of Chinese students in British higher education, Edwards and Ran (2006) found that the main reason expressed for studying in the United Kingdom was instrumental-the need for educational qualifications to increase employment opportunities and social status. Zhou (2014) also suggested something similar in reporting on the persistent motivation of six Chinese doctoral students in the United States.

The two types of motivations should not, however, be dichotomised; they coexist at the same time in Chinese students' minds. Two studies illustrate that extrinsic and intrinsic motives can coexist and flow in two directions over time (Gao, 2008; Zhou, 2014). In a study that explored the language learning motivations of undergraduates from mainland China studying in a Hong Kong institution, viewing learner motivation as a dynamic construct, Gao (2008) analysed their motivational discourses respectively in mainland China and in Hong Kong, and found that despite still having extrinsic motives, the students became more intrinsically motivated to learn English after arriving in Hong Kong. He revealed that contextual factors (e.g. parents, teachers and peers) and self-determined elements (e.g. ideal self) were closely interrelated in their motivational process. This is confirmed again in a study by Zhou (2014), which found that during their studies, the Chinese doctoral students became more extrinsically motivated to do research (e.g. gaining permanent residence in the United States and fulfilling filial piety).

Moreover, the two studies identified ideal self as a source of learning motivations. As Wenger (1998, p.178) points out, "by taking us into the past and carrying us into the future, (imagination) can recast the present and show it as holding unsuspected possibilities." Compared with Gao's (2008) study, however, Zhou's (2014) findings focused more on the negative influence of ideal self than the positive, adding that a mismatch between Chinese doctoral students "overly broad and optimistic expectations" of American PhD research 
and their actual experiences partly aroused their dissatisfaction with their studies, thus demotivating them (p.183). As Wenger (1998, p.178) suggested, "disconnected and ineffective" imagination "runs the risk of losing touch with the sense of social efficacy by which our experience of the world can be interpreted as competence."

Although previous research projects, such as the two studies above, highlight the influence of learning contexts on Chinese research students' motivations by analysing their narratives, they do not reflect on the roles that family life and previous experiences play in shaping and constructing their motivations. Their family life and previous experiences may be influential in making the decision of pursuing a doctoral degree overseas. In a study examining nine Chinese families in Shanghai, Zhang (2013), for instance, drew attention to how Chinese parents' life and learning experiences significantly influenced their decision to send their teenage children to study in New Zealand.

Furthermore, current literature does not acknowledge Chinese doctoral students' agency and nor does it explore how they interact with wider contexts where they live and subsequently succeed in gaining access to overseas education. This proposed research will examine how they pave the way for their studies.

\section{UNIVERSITY LIFE: TWO PARADIGMS OF ADAPTATION AND SELF- FORMATION}

Much published research has been conducted from an adaptation perspective; international student learning is viewed as "a process of 'adjustment' or 'acculturation' to the requirements and habits of the host country" (Marginson, 2014, p.8). Numerous studies (e.g. Briguglio \& Smith, 2012; McClure, 2005; Zhang, 2016; Zhou, 2014) have explored the intercultural experiences of Chinese doctoral students, with more attention focused on negative experiences-academic and pastoral issues, such as limited proficiency in English, being silent and ignored in class, lacking advice and support, being marginalised in the relationship with supervisors, being unaware of institutional-level sources of advice and being isolated and lonely. In this paradigm, which implies the widespread cultural superiority of English language education systems (Marginson, 2014), Chinese international doctoral students, like other Asian students, seem to be stereotyped as students with learning and social deficits.

An exception is the study by Ye and Edwards (2015) which explored how Chinese doctoral students adapt to the environment in the United Kingdom. Their findings show that the students proactively used various coping strategies to meet challenges and adjust to the new environment, and that reflexivity and autonomy featured prominently in their lives in the United Kingdom, thus facilitating the construction of their self-identities. This study, with its focus on students' agency and reflexivity as well as their identity, is supported by Marginson's self-formation paradigm, in which international students are seen as self-forming persons who are "strong agent(s) piloting the course of (their lives)" (2014, p.12). He suggests a need for a greater awareness of the assumption that international education is "a process of self-formation within conditions of disequilibrium in which student subjects manage their lives 
reflexively, fashioning their own changing identities, albeit under social circumstances largely beyond their control" (p.6). The concepts of identity and agency are thus viewed as useful tools in understanding the international student experience.

In a similar fashion to Ye and Edwards (2015), a small but growing body of studies has examined the significant roles of agency and identity in the international student experience. A study by Wang (2012) on the development of eight Chinese undergraduate students at Canadian universities also discussed the significant role of agency in the process of transformation and found that the students actively shaped themselves in new learning environments, in terms of their academic skills and identities. Jiang et al. (2010) suggest similar findings in reporting on Chinese academic staff working in two British universities. Moreover, Gu and Schweisfurth's (2015) work on Chinese graduate returnees who previously studied at British universities indicates that agency is a key force for the dramatic shifts of the Chinese returnees' perspectives, skills and identities not only during their studies but also after their studies, suggesting "its sustainability over time" (p.19).

The existing literature highlights the positive impact of studying abroad on international students. For example, Gu and Schweisfurth's (2006) work on Chinese students at British universities and Wang's (2012) research on Chinese undergraduate students in Canada emphasise the positive influence, such as the broadening of horizons, the increase of self-confidence and selfresponsibility and the change in their perceptions of themselves. Nevertheless, it may be assumed that the sojourn can also have a negative influence on international students. This proposed research, will therefore explore not just positive influences, but also the negative.

\section{'I am not her mother'}

Current literature tends to spotlight the negative aspects of the student/supervisor relationship, in terms of insufficient guidance, support and attention from supervisors (e.g. Zhang, 2016), mismatched research interests or working style (e.g. Zhou, 2014) and emotional and physical distance of supervisors (e.g. McClure, 2005). Zhou suggests that the negative interaction with supervisors can demotivate Chinese doctoral students in the United States, causing student dissatisfaction. In a study exploring Chinese research students' experiences of supervision in Singapore, McClure points out that the students' negative experiences of supervision stem from unfulfilled initial expectations (of supervision), which originate from the home culture. Unfulfilled initial expectations are, however, not limited to the Chinese students.

Based on a study of Chinese students and supervisors in the United Kingdom, Edwards and Ran (2006) indicated that cultural differences can lead to misunderstanding on both sides. For instance, believing that a hierarchical relationship between student and teacher, Chinese students hold their teachers in high esteem (Edwards \& Ran, 2006). They respectfully address their supervisors by their titles not their first names. Some Western academics perhaps feel uncomfortable to be addressed this way by their Chinese students: 
"Chinese students are too polite. I asked them not to call me 'Professor'. Just call me by my first name. [But] they still call me 'Professor'"1.

Despite having a hierarchic relationship with supervisors, in line with the Confucian view of the relationship between student and teacher, Chinese students expect to develop emotional bonds and professional closeness with their teachers (McClure, 2005; Edwards \& Ran, 2006). This expectation of closeness might well include an expectation of undertaking joint research with their supervisors. Nevertheless, in overseas doctoral education, students are expected to conduct independent research (McClure, 2005; Zhou, 2014). Western supervisors expect a certain distance from students: "One of my Chinese students told me about her personal life in Australia and sometimes she cried in meetings. I am not her mother" ${ }^{2}$. As Edwards and Ran suggest, Western teachers tend to view Chinese students' attempt to "engage their attention outside the classroom and office hours as demanding" (2006, p.7). This, to some degree, could cause Chinese students' hesitation to contact their supervisor in order to discuss their research (McClare, 2005).

To summarise the negative supervisory experiences of the Chinese research students in her study, McClure (2005) used the concept of marginalisation to describe the Chinese students in their relationships with supervisors. She defined marginalisation as a feeling of anxiety about the students' adaptation to the relationships and new approaches to teaching and learning, and about their ability to undertake independent research and communicate with supervisors. Wenger (1998), on the other hand, perceived marginality as disempowering-in one case of the interaction of participation and non-participation in a community of practice, Wenger (1998) viewed marginality as "a form of non-participation [that] prevents full participation...it is the non-participation aspect that dominates and comes to define a restricted form of participation" (p.166).

Wenger distinguishes marginality (which is disempowering) from peripherality, which is empowering. "Some degree of non-participation is necessary to enable a kind of participation that is less than full...it is the participation aspect that dominates and defines non-participation as an enabling factor of participation" (p.165). This is an argument for agency. Wenger points out "whether non-participation becomes peripherality or marginality depends on relations of participation that render non-participation either enabling or problematic" (p.167). McClure (2005), despite her interest in marginalisation, did not see the potential positive effects of agency that Wenger (1998) saw in peripherality-not exploring how Chinese research students handle the tension in their relationships with supervisors. The concepts of marginality and peripherality have implications for doctoral supervision. Supervision can encourage the student who experiences marginality to use encouragement and their own agency to become 'peripheral' rather than 'marginalised'.

There have been emerging voices spotlighting student agency and identity in the supervisory relationship. Singh (2009) suggested that Western academic staff supervising Chinese doctoral students doing educational

\footnotetext{
${ }^{1}$ Personal communication, 30 June 2015.

2 Personal communication, 02 July 2015.
} 
research should acknowledge their cross-cultural uncertainty and encourage Chinese doctoral students to use their own intelligence and intellectual heritage to produce knowledge, thus enhancing these students' capabilities and strengthening their professional identities. Robinson-Pant (2009) also recommended that Western universities need to learn how to respond positively to the different research practices international research students engage in their home institutions. In her research into Chinese and New Zealand higher education, Jiang (2005) indicated that the interplay between the perspectives of international students and host academic staff may lead to the widening of the intellectual horizons of the academic staff.

In my proposed research, I will use Wenger's (1998) definitions of marginality and peripherality to illustrate Chinese doctoral students' initial interaction with supervisors. I perceive students' interaction with their supervisors as a process of learning. Initial non-participation does not mean that the students will remain marginalised. For Chinese doctoral students, as newcomers who may expect and/or be expected to fully participate in their interaction with supervisors, non-participation is an opportunity for learning (Wenger, 1998). For instance, in the earlier cited case of the British professor, his Chinese students perhaps experienced the coexistence of non-participation (calling him 'Professor') and participation (calling him by his first name). They were torn between the conflicting values of their Chinese practices and their new community (a British university). As Wenger (1998, p.167) pointed out, "the mix of participation and non-participation through which we define our identities reflects our power as individuals and communities to define and affect our relations to the rest of the world." Briefly, my proposed research aims to explore if Chinese students eventually learn to talk in the manner of full participants in a new community of practice, and how Chinese doctoral students tackle the tension - external and internal, encountering struggles and challenges arising from their interaction with supervisors and lecturers. It also examines how Chinese doctoral students perceive the influences of and changes in their identities, if at all, during the process.

\section{'Becoming a member of the research community was a highlight for me'}

A growing body of Western literature addresses the importance of university- and student- based support for international students' transition (provided in host contexts) in helping solve the problems they encounter, meeting their practical, social and academic needs and further facilitating their integration into new environments. For example, innovative course designs, such as culturally inclusive pedagogy (Blasco, 2015) and the expansion of orientation programmes (McDonald, 2014), can facilitate international students' familiarity not only with the host learning culture but also with potential differences between the host educational culture and the home, thus helping them adjust to host educational systems. Effective student support policies, including social integration initiatives (Owens \& Loomes, 2010) and the development of student societies (Menzies \& Baron, 2014), can assist international students in socialising with local people and further developing social networks, thus facilitating their psychological well-being and effective learning.

These are echoed in a brief autobiographical essay on the experience of a Malaysian doctoral graduate doing a PhD in New Zealand (Zahidi, 2014). She 
highlighted the significant influence of support services (e.g. preparatory and orientation programmes, the Campus Coach programme and student learning support services) provided by her New Zealand university. These ensured her smooth transition to her new environment and on the successful completion of her research. She also suggested the support services be continuous over the whole process of learning-pre-arrival, at the beginning, and ongoing during the study period. In his own reflective accounts of being a Chinese PhD student in New Zealand, Jiao (2014) also emphasised the importance of fully using resources available in maintaining his motivation for doing research and successfully completing his studies.

Jiao, like Zahidi (2014), demonstrated perseverance, and was prepared to adapt himself to the new learning environment. His motivation to adapt would be based not only on achieving his goal- "becoming a member of the research community was a highlight for me" (p.213), but also on having to adjust. His advice to (potential) Chinese postgraduate students is:

If you choose to undertake postgraduate study in a different country, with different languages and customs, you will constantly face challenges in adapting to different cultural norms and academic conventions. You have to develop coping strategies both to achieve your own goals and to meet university requirements. (Jiao, 2014, p.217)

The have-to-adapt motivation is supported by $\mathrm{Gu}$ and Schweisfurth's (2006) work that found similar evidence among their sample of Chinese students at British universities. Despite having to adapt, in order to meet his own academic and social needs, Jiao (2014) proactively developed two coping strategies for participating in the new academic practice: 'sufficient preparation' and 'maximum utilisation of the resources available'. He took the following action: using his university website, reading literature about the experiences of international students (and particular Chinese students), meeting with staff at the Chinese Centre to learn about the experiences of Chinese students, attending almost all the programmes, workshops and seminars, talking to academic staff and other students, and being a research assistant. Jiao's participation in the new academic practice involved 'action' and 'connection' (Wenger, 1998, p.55), through which he gained "a sense of belonging (and) a sense of place" (Jiao, 2014, p.213).

In their autobiographical accounts of the experiences of undertaking doctoral research, Jiao (2014, p.211) and Zahidi (2014) built their own images of motivated and adaptable Asian students, taking their initiative in learning how to behave and talk in the New Zealand academic environment and successfully becoming familiar with the practices through trial and error. Both evidently derived a high sense of agency from their engagement in the new environment and, as a result, they had more confidence and independence than previously.

Neither Jiao's (2014) nor Zahidi's (2014) accounts explained, however, what the 'trial and error' were. In his reflective accounts of own academic writing experiences during his overseas postgraduate studies, Shamsuzzaman (2014), did describe the 'trial and error' as a process of struggle with himself being constantly caught between his Bangladeshi writing ideology and style and those of the United States and New Zealand. In her study exploring international PhD 
students' perspectives on differences between academic cultures of their British and home universities, Robinson-Pant (2009) illustrated a similar struggle overseas PhD students faced-being caught between two different practices.

Tensions remain, however. Conforming to a new learning environment to complete a doctoral degree not only requires students to be autonomous agents who choose their topics and methodologies and do their projects (Middleton, 2001), but also involves them being "subjected to authority, to degree regulations, to the convention of thesis writing within a field, and to examinations" (Foucault, 1977, 1982, cited in Middleton 2001, p.4). Less literature on Chinese overseas doctoral students has examined how they submit to the Western academic tradition. My proposed study thus intends to explore the space between complete acceptance of Western educational practices and struggle to maintain traditional and contemporary Chinese practices. Shamsuzzaman's (2014) experience of initial non-participation is significant because "this experience of non-participation is aligned with a trajectory of (later) participation" in Western academic practices" (Wenger, 1998, p.165). As Wenger pointed out, "it is the interaction of participation and non-participation that renders the experience consequential" (p.165). Therefore, this study not only addresses Chinese overseas doctoral students' experiences of being able to adapt to and participate in host academic practices, but also explores their experiences of non-participation.

\section{CONCLUSION}

This proposed study of Chinese doctoral students in New Zealand starts from the perspective of the self-formation paradigm and positions these students as active participants in host academic practices. This does not mean ignoring the two-way typology of their extrinsic and intrinsic motives for studying abroad and the challenges and difficulties they face, which much of previous research has examined, but being more focused on how they pave the way for their overseas studies and how they cope with them and how they develop themselves in the process. That is, it spotlights their action, what they do facing these struggles and challenges, and their agency-being able to take autonomous and empowered action (Ecclestone, 2007). This, as Biesta and Teddar (2007) indicated, is achieved through international students' active engagement in host academic practices, a position I agree with. As they pointed out:

Agency is not something that people have; it is something that people do. It denotes a 'quality' of the engagement of actors with temporalrelational contexts-for-action, not a quality of the actors themselves. (p.136)

Chinese doctoral students' agency is thus viewed as not static but developing and changing over time. Their can-do ability could depend on the interplay of their motivation for learning, available resources and wider contextual factors. This has been endorsed by Jiao (2014, p.217), highlighting the significance of fully utilising resources available in his PhD studies: "through active participation, you discover the powerful parts of you and your adventure that you did not know were there". 
Manuscript Submitted: March 30, 2016

Revised Manuscript Received: June 23, 2016

Revised Manuscript Accepted: July 28, 2016 


\section{REFERENCES}

Azmat, F., Osborne, A., Rossignol, K. L., Jogulu, U., Rentschler, R., Robottom, I. \& Malathy, V. (2013). Understanding aspirations and expectations of international students in Australian higher education. Asia Pacific Journal of Education, 33(1), 97-111. Retrieved on 24 December 2014 from DOI: $10.1080 / 02188791.2012 .751897$

Biesta, G., \& Tedder, M. (2007). Agency and learning in the life course: Towards an ecological perspective. Studies in the Education of Adults, 39 (2), 132-149.

Blasco, M. (2015). Making the tacit explicit: rethinking culturally inclusive pedagogy in international student academic adaptation. Pedagogy, Culture \& Society, 23(1), 85-106. Retrieved on 24 December 2014 from DOI: $10.1080 / 14681366.2014 .922120$

Briguglio, C. \& Smith, R. (2012). Perceptions of Chinese students in an Australian university: are we meeting their needs?. Asia Pacific Journal of Education, 32(1), 17-33. Retrieved on 23 December 2014 from DOI: 10.1080/02188791.2012.655237

Croll, E. (1995). Changing Identities of Chinese Women: Rhetoric, Experience and Self-perception in Twentieth-century China. Hong Kong: Hong Kong University Press.

Ecclestone, K. (2007). Editorial - An identity crisis? Using concepts of 'identity', 'agency' and 'structure' in the education of adults. Studies in the education of adults, 39 (2), 121-131.

Edwards, V. \& Ran, A. (2006). Meeting the needs of Chinese students in British higher education. Retrieved from https://blogs.shu.ac.uk/internationalnetwork/files/2013/07/MeetingTheNe eds.pdf

Gao, X. S. (2008). Shifting motivational discourses among mainland Chinese students in an English medium tertiary institution in Hong Kong: A longitudinal inquiry. Studies in Higher Education, 33(5), 599-614. Retrieved on 01 January 2015 from DOI: 10.1080/03075070802373107

Goff, D. J. \& Carolan, T. M. (2013). The intersection of gender and culture in Chinese international student couples. Journal of Feminist family therapy, 25(3), 141-164. Retrieved on 24 December 2014 from DOI: 10.1080/08952833.2013.777879

Gu, Q. \& Schweisfurth, M. (2006). Who adapts? Beyond cultural models of 'the' Chinese learner. Language, Culture and Curriculum, 19(1), 74-89. Retrieved on 21 October 2015 from 10.1080/07908310608668755

Gu, Q. \& Schweisfurth, M. (2015). Translational connections, competences and identities: experiences of Chinese international students after their return 'home. British Educational Research Journal, 41(6), 947-970. Retrieved on 21 October 2015 from DOI: 10.1002/berj.3175 
Jiang, X. L., Napoli, R. D., Borg, M., Maunder, R., Fry, H. \& Walsh, E. (2010). Becoming and being an academic: the perspectives of Chinese staff in two research-intensive UK universities. Studies in Higher Education, 35(2), 155-170. Retrieved on 01 January 2015 from DOI: 10.1080/03075070902995213

Jiang, X. P. (2005). Globalisation, internationalisation and the knowledge economy in higher education: A case study of China and New Zealand. PhD thesis, University of Auckland. Retrieved on 08 June 2016 from http://wwwlib.umi.com/dissertations/fullcit/3189279

Jiao, M. X. (2014). From China to Aotearoa New Zealand and back. In C. McMaster \& C. Murphy (Eds.), Postgraduate study in Aotearoa New Zealand: surviving and succeeding (pp.209-218). Wellington, New Zealand: NZCER Press.

Kennedy, P. (2002). Learning cultures and learning styles: myth-understandings about adult (Hong Kong) Chinese learners. International Journal of Lifelong Education, 21(5), 430-445. Retrieved on 16 November 2014 from DOI: 10.1080/02601370210156745

Leder, G. C. \& Forgasz, H. J. (2004). Australian and international mature students: the daily challenges. Higher Education Research \& Development, 23(2), 183-198. Retrieved on 24 December 2014 from DOI: 10.1080/0729436042000206654

Lian, H.P. (2014). The post-1980s generation in China: exploring its theoretical underpinning. Journal of Youth Studies, 17 (7), 965-981. Retrieved on 03 June 2016 from http://dx.doi.org/10.1080/13676261.2013.878786

Lovell, R. B. (1989). Adult learning. London: Routledge.

Ma, J., Hu, Z. H. \& Goclowska, M. A. (2016). Cultural orientation in China: differences across five generations of employees. Social Behaviour and Personality, 44(4), 529-540. Retrieved on 03 June 2016 from http://dx.doi.org/10.2224/sbp.2016.44.4.529

Marginson, S. (2014). Student self-formation in international education. Journal of Studies in International Education, 18(1), 6-22. Retrieved on 27 June 2015 from DOI: 10.1177/1028315313513036

Mazzarol, T. \& Soutar, G. N. (2002). "Push-pull” factors influencing international student destination choice, International Journal of Educational Management, 16(2), 82-90. Retrieved on 17 June 2016 from http://dx.doi.org/10.1108/09513540210418403

McClure, J. W. (2005). Preparing a laboratory-based thesis: Chinese international research students' experiences of supervision. Teaching in Higher Education, 10(1), 3-16. Retrieved on 21 February 2016 from DOI: $10.1080 / 1356251052000291530$

McDonald, I. (2014). Supporting international students in UK higher education institutions. Perspectives: Policy and Practice in Higher Education, 18(2), 62-65. Retrieved on 24 December 2014 from DOI: 10.1080/13603108.2014.909900 
Menzies, J. L. \& Baron, R. (2014). International postgraduate student transition experiences: the importance of student societies and friends. Innovations in Education and Teaching International, 51(1), 84-94. Retrieved on 24 December 2014 from DOI: 10.1080/14703297.2013.771972

Middleton, S. (2001). Educating researchers: New Zealand education PhDs, 1948-1998: 'State-of the-Art' monograph No. 7. Wellington, New Zealand: New Zealand Association for Research in Education.

Moore, R. L. (2005). Generation Ku: individualism and China's millennial youth. Ethnology, 44(4), 357-376. Retrieved on 03 June 2016 from DOI: $10.2307 / 3774095$

Owens, A. \& Loomes, S. (2010). Managing and resourcing a program of social integration initiatives for international university students: what are the benefits?. Journal of Higher Education Policy and Management, 32(3), 275-290. Retrieved on 24 December 2014 from DOI: $10.1080 / 13600801003743364$

Robinson-Pant, A. (2009). Changing academics: exploring international PhD students' perspectives on 'host' and 'home' universities. Higher Education Research and Development, 28(4), 417-429. Retrieved on 21 February 2016 from DOI: 10.1080/07294360903046876

Shamsuzzaman, M. (2014). Crossing borders: writing in a second language. In C. McMaster \& C. Murphy (Eds.), Postgraduate study in Aotearoa New Zealand: surviving and succeeding (pp.219-228). Wellington, New Zealand: NZCER Press.

Singh, M. (2009). Using Chinese knowledge in internationalising research education: Jacques Rancière, an ignorant supervisor and doctoral students from China. Globalisation, Societies and Education, 7 (2), 185201. Retrieved on 21 February 2016 from DOI: 10.1080/14767720902908034

Sun, J. M. \& Wang, X. (2010). Value differences between generations in China: A study in Shanghai. Journal of Youth Studies, 13 (1), 65-81. Retrieved on 03 June 2016 from DOI: 10.1080/13676260903173462

Swain, J., \& Hammond, C. (2011). The motivations and outcomes of studying for part-time mature students in higher education. International Journal of Lifelong Education, 30(5), 591-612. Retrieved on 12 November 2014 from DOI: 10.1080/02601370.2011.579736

Wang, Y. (2012). Transformations of Chinese international students understood through a sense of wholeness. Teaching in Higher Education, 17(4), 359370. Retrieved on 23 December 2014 from DOI: 10.1080/13562517.2011.641004

Wenger, E. (1998). Communities of practice: learning, meaning, and identity. Cambridge: Cambridge University Press.

Ye, L. \& Edwards, V. (2015). Chinese overseas doctoral student narratives of intercultural adaptation. Journal of Research in International Education, 14(3), 228-241. Retrieved on 15 February 2016 from DOI: $10.1177 / 1475240915614934$ 
Zahidi, A. (2014). Studying at a Western university: An Asian perspective. In C. McMaster \& C. Murphy (Eds.), Postgraduate study in Aotearoa New Zealand: surviving and succeeding (pp.199-208). Wellington, New Zealand: NZCER Press.

Zhang, V. J. (2013). A narrative study of lived experiences of Chinese international students and their parents. PhD thesis, AUT University. Retrieved on 13 March 2016 from http://aut.researchgateway.ac.nz/handle/10292/8513

Zhang, Y. (2016). International students in transition: voices of Chinese doctoral students in a U.S. research university. Journal of International Students, 6(1), 175-194. Retrieved on 09 February 2016 from http://search. .proquest.com/docview/1783941954 ?accountid=8440

Zhou, J. (2014). Persistence motivations of Chinese doctoral students in science, technology, engineering, and math. Journal of Diversity in Higher Education, 7(3), 177-193. Retrieved on 09 February 2016 from http://dx.doi.org/10.1037/a0037196 


\section{ABOUT THE AUTHOR(S)}

QUN DING

Auckland University of Technology

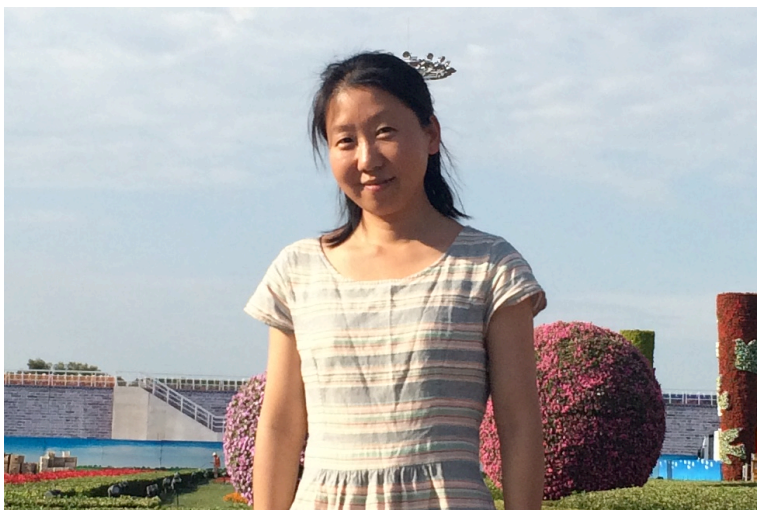

A research fellow at the Auckland University of Technology School of Education, Qun Ding completed her $\mathrm{PhD}$ at the University of Sheffield. Experiences at a Chinese Open University and in Europe led to her focus on adult learning and the cross-cultural experiences of international students, including the experiences of Chinese overseas doctoral students in New Zealand.

Email: dingqun cn@hotmail.com 